\title{
Overview of SARS-CoV-2 and COVID-19 pandemic
}

\author{
Nada Abdullah Alharbi ${ }^{1 \star}$ and Thamir Saad Alsaeed ${ }^{2}$ \\ ${ }^{1}$ Department of Basic Medical Sciences, Unaizah College of Medicine and Medical Sciences, Qassim University, \\ Qassim, Kingdom of Saudi Arabia. \\ 2Department of Pathology, College of Medicine, Qassim University, P.O. Box 6655, Buraidah 51452, Qassim, \\ Saudi Arabia. \\ Email: na.alharbi@qu.edu.sa
}

Received 17 June 2020; Received in revised form 15 October 2020; Accepted 29 November 2020

\begin{abstract}
Coronavirus disease 2019 (COVID-19) which caused by severe acute respiratory syndrome-coronavirus-2 (SARS-CoV2 ) is the prevailing global health issue at this time, spreading rapidly despite various containment efforts. It is first reported in Wuhan, China in December 2019 and the total number of cases has reached 7,064,230 with 404,585 total deaths globally to date (June 7, 2020). SARS-CoV-2 is reported closely related to SARS-CoV and MERS-CoV, the virus causes only mild symptoms in the majority of cases. However, it can progress to pneumonia and acute respiratory distress syndrome (ARDS), eventually leading to multiple organ dysfunction, the major cause of mortality among affected patients. The primary modes of transmission include droplet and contact infection, and possibly respiratory aerosols in settings where aerosol-generating procedures (AGPs) occur. Diagnosis mainly relies on detecting the viral RNA in nasopharyngeal and oropharyngeal specimens, combined with imaging techniques such as chest X-ray and computerized tomography (CT) scan. Currently, no empirical therapy or vaccine is available yet for the virus, and supportive measures remain the mainstay of treatment. Information about the virus is being updated every day. This review article summarizes the current knowledge surrounding the outbreak, including epidemiology, virological facts, pathogenesis, clinical findings, diagnostic criteria, and currently available therapeutics and vaccines, with a special emphasis on Middle Eastern countries including Saudi Arabia.
\end{abstract}

Keywords: COVID-19, SARS-CoV-2, Middle East, Saudi Arabia, global health emergency

\section{INTRODUCTION}

What started as a mysterious respiratory illness, not readily recognized, has taken the world by surprise, and virtually no country has been able to escape its devastating effects. The earliest cases of COVID-19 can be traced back to November 17, 2019, in Wuhan, the capital city of Hubei province, China (Jackwerth, 2020). However, it was not until December 31, 2019 that several cases of a novel pneumonia-like illness that resisted treatment were reported to the World Health Organization (WHO, 2020a). Shortly afterward, the virus was identified based on sequence-based analysis of the isolates from patients and named as severe acute respiratory syndrome-coronavirus-2 (SARS-CoV-2) by the International Committee on Taxonomy of Viruses (previously called 2019-nCoV). The disease caused by it known as coronavirus disease 2019 (COVID-19) (WHO, 2020b; Lai et al., 2020). Similar viruses from the coronavirus family have been known to cause diseases in humans, with notable examples being the severe acute respiratory syndrome (SARS) outbreak in 2002 (Anderson et al., 2004) and the subsequent 2012 Middle East respiratory syndrome coronavirus (MERS) outbreak in 2012 (Assiri et al., 2013).

Even though there are several theories about the origin of SARS-CoV-2, none of them satisfactorily answers the question. Although it is thought to have emerged from the South China seafood market in Wuhan, the evidence for this theory is not conclusive (Zhang et al., 2020a).

After the initial reports of the outbreak, the WHO established an Incident Management and Support team across all three of its levels to deal with the situation. Shortly after, on January 30, 2020, when the reports of human-to-human transmission of the virus were confirmed, the WHO declared is a Public Health Emergency of International Concern (PHEIC). As the situation continued to escalate despite the efforts to contain the virus, the COVID-19 was declared a pandemic on March 11, 2020 (WHO, 2020a).

This review summarizes the current understanding of COVID-19 and SARS-CoV-2. Based upon recent scientific publications, this inclusive review covers the 
fundamental biology of SARS-CoV-2 along with its potential zoonotic origins, pathology, risk factors, pathophysiology, transmissibility, epidemiology, contagiousness, and development of the infection and immunity processes. It also provides an overview of the global transmission of this virus. As our knowledge about SARS-CoV-2 is rapidly evolving, readers are advised to update themselves regularly. Traditional and modern molecular and clinical diagnostic techniques, along with the diverse treatment measures for COVID-19, are also discussed herein. Up-to-date knowledge of the COVID-19 pandemic has been summarized, with an emphasis on its effects in humans. This multidisciplinary review includes information from a large number of literature articles concerning SARS-CoV-2.

Specifically, genetic characteristics, histopathology, immune responses, and virology are discussed. The clinical manifestations, radiological features, and laboratory findings are also examined, in addition to the multiple complications of COVID-19. This discussion is followed by a review of the existing literature regarding ongoing trials and adjunctive therapies. The broader aspects of coronaviruses and the clinical characteristics, evaluation methods, and treatment of COVID-19 patients are presented. This paper also offers resources with which to raise awareness among primary and secondary healthcare professionals in the course of the current crisis. A focus on the most recent clinical data will help guide the appropriate prevention, management, and treatment of COVID-19 patients across the globe.

\section{Virology facts}

Coronaviruses, named so due to the crown-like projections on their surface, can be pathogenic for birds, mammals, and humans. According to the classification by the International Committee for Taxonomy of Viruses (ICTV), they belong to order Nidovirales, family Coronaviridae, and subfamily Orthocoronavirinae. In addition to SARS-CoV-2, there are now seven coronaviruses known to cause disease in humans (Ahmad and Rodriguez-Morales, 2020). Of these, 229E, OC43, NL63, and HKU1 only cause mild symptoms, whereas SARS-CoV, MERS-CoV, and SARS-CoV-2 are known to be highly pathogenic (Malik, 2020). SARS-CoV2 , like the other coronaviruses, is spherical and enveloped. Within its nucleocapsid, positive-sense singlestranded RNA is contained. Of the four genera $(\alpha, \beta, y, \delta)$ of human coronaviruses, SARS-CoV-2 belongs to $\beta-\mathrm{CoV}$ and shows a close resemblance to two bat-derived coronaviruses, bat-SL-CoVZC45 and bat-SL-CoVZXC21. Like the other two major pathogenic coronaviruses SARSCoV and MERS-CoV, SARS-CoV-2 is also thought to have originated in bats. Full-length genome sequences acquired from infected patients seem to fortify this idea, as SARS-COV-2 shares a $79.6 \%$ sequence identity to SARS-CoV; additionally, it is $96 \%$ identical to a bat coronavirus at the whole-genome level (Zhou et al., 2020). The possibility of an intermediate host facilitating the transmission of the virus to humans cannot be ruled out, as civet cats and camels acted as intermediate hosts with SARS-CoV and MERS-CoV, respectively.

There are four major coronaviral structural proteins: the spike (S), membrane (M), envelope (E), and the nucleocapsid $(\mathrm{N})$ protein. All these are encoded by the 3 end of the genome, having distinctive functions vital for its virulence. The spike (S) protein mediates the attachment of the virus to the specified receptors on the surface of host cells, resulting in the subsequent fusion of the virus and entry into the host cell. The membrane (M) protein has a structural role in maintaining the shape of the viral envelope, while the envelope $(\mathrm{E})$ protein plays a role in replication, during assembly and budding. The nucleocapsid (N) protein binds with the RNA genome and contributes to assembly and budding. The viral replication begins after the fusion and entry into the host cell. The first step is the translation of the replicase gene from the viral RNA genome, followed by translation and assembly of replicase complexes. After the initial formation of subgenomic RNA, subsequent encapsidation occurs, completing the process of replication. The mature viruses synthesized are then transported in vesicles to the cell surface and released by exocytosis, allowing them to infect more host cells (Shang et al., 2020).

\section{Pathogenesis}

\section{Attachment to the host cell}

Even though bats are believed to be the source for SARS-CoV-2, the exact molecular mechanism that led to its transmission to humans still remains unknown. Both SARS-CoV and SARS-CoV-2 attach to the same receptor in humans, angiotensin-converting enzyme 2 (ACE2). The receptor recognition mechanism of SARS-CoV-2 is a key feature in regulating its infectivity, pathogenesis, and host range. In SARS-CoV-2, the receptor-binding domain (RBD) of the spike (S) protein shows certain structural differences from its SARS-CoV counterpart. These structural differences likely account for its increased ACE2 binding affinity and high infectivity compared to SARS-CoV (Shereen et al., 2020). These findings led to the question of if the use of ACE inhibitors and angiotensin-receptor blockers (ARBs) will influence the risk of COVID-19 infection in any way. The current evidence in this regard has failed to establish any link between the two (Mancia et al., 2020).

\section{Viral replication}

The initial viral replication seems to occur in the upper respiratory tract, in the nasal and pharyngeal epithelium, with subsequent replication in the lower respiratory tract and gut mucosa (Jin et al., 2020).

\section{Lung pathology}

The pulmonary pathological findings obtained from many severe cases are characteristic of acute respiratory distress syndrome (ARDS). The reports of one patient 
showed bilateral pulmonary diffuse alveolar damage combined with cellular fibromyxoid exudates. The desquamation of pneumocytes and hyaline membrane formation was also observed. There were bilateral interstitial inflammatory infiltrates rich in lymphocytes. Additionally, viral cytopathic-like changes were identified. Upon CT scan, ground-glass opacities and subsegmental areas of consolidation are a common finding among patients (Jin et al., 2020). These findings closely resemble the pathological changes observed in SARS and MERS (Jin et al., 2020). However, gastrointestinal findings such as diarrhea and vomiting are more frequently associated with SARS-CoV-2 than with SARSCoV and MERS-CoV (Rothan and Byrareddy, 2020). Also, massive bilateral mucus secretions found postmortem in a patient were unique to SARS-CoV-2 (Jin et al., 2020). Biopsy specimens from the liver and heart of the same patient were inconclusive (Xu et al., 2020). ARDS, a life-threatening condition, is encountered only in severe cases of COVID-19 requiring mechanical ventilation and often leading to death. The entry and initial replication of the virus can cause excessive cell damage and vascular damage, resulting in the abundant production of pro-inflammatory cytokines and chemokines leading to a cytokine storm, which may be associated with immune-mediated damage, ARDS, and poorer outcomes (Jin et al., 2020).

\section{Epidemiology}

\section{Mode of transmission}

Even though much information is being shared regarding precautionary measures, detection, testing, and management of the potential victims, it is largely based on what we know about SARS-CoV and MERS-CoV, and there is still a lot to learn about SARS-CoV-2. The current information on the virus suggests that it is transmitted through respiratory secretions via direct or indirect contact. Direct contact with respiratory droplets from infected persons or indirect contact with fomites contaminated by secretions from infected persons are the primary modes of transmission (Cai et al., 2020; Lai et al., 2020; Parry, 2020; Riou and Althaus, 2020). It can gain access to the body through the mucosal surfaces of mouth, nose, and eyes when contaminated fingers touch the face (Lam et al., 2020; Zhang et al., 2020b). Based on the idea that the virus is primarily transmitted through large respiratory droplets, the United States Centers for Disease Control and Prevention (CDC) recommends maintaining a distance of at least six feet (1.8 meters) to minimize the risk of contagion (Centers for Disease Control, 2019). However, recent studies on aerosol transmission suggest that this distance may not be enough (Setti et al., 2020).

Whether airborne transmission of SARS-CoV-2 is possible or not is currently a matter of debate. When 75,465 COVID-19 positive cases from China were analyzed, airborne transmission was not reported among them. Airborne transmission is distinct from droplet transmission; respiratory droplets, with particles $>5-10 \mu \mathrm{m}$ in diameter, play an essential role in transmission either via inhalation or contamination of objects in proximity. Airborne transmission, on the other hand, refers to the presence of pathogens in droplet nuclei, with particles $<5$ $\mu \mathrm{m}$ in diameter. These can remain suspended in the air for much more extended periods, enabling the transmission over distances greater than 1.8 meters (WHO, 2020c). Airborne transmission of SARS-CoV-2 seems to be possible in certain circumstances in clinical settings where aerosol generating procedures (AGPs) are being performed. These procedures include endotracheal intubation, open suctioning, non-invasive positivepressure ventilation, tracheostomy, bronchoscopy, administration of nebulized treatment, manual ventilation, disconnection of a patient from ventilation, and cardiopulmonary resuscitation (WHO, 2020c).

Some scientific studies have been able to provide preliminary data on the presence of SARS-CoV-2 in the air. One experimental study published in the New England Journal of Medicine tested the aerosol stability of SARS-CoV-2. The aerosols were generated by using a three-jet Collison Nebulizer, then fed into a Goldberg drum in order to mimic an aerosolized environment. The machine used, however, was not able to replicate the condition created by the human cough. The results indicated that SARS-CoV-2 could remain viable in aerosol particles for up to three hours. However, these results are based on an artificial aerosol-generating procedure and do not reflect clinical settings where actual AGPs are performed (van Doremalen et al., 2020). In addition, other studies have collected air samples from the facilities where COVID-19 positive symptomatic patients were admitted but did not detect SARS-CoV-2 RNA in the samples (Cheng et al., 2020; Ong et al., 2020). However, these results are rendered dubious due to conflicting information obtained from several other studies. The higher aerosol and surface stability of SARS-CoV-2 compared to SARS-CoV is well established, leading researchers to conclude that airborne transmission of the virus over a long distance is possible, as it remains viable in aerosols in infectious form for hours (van Doremalen et al., 2020). Moreover, several lines of evidence suggest that it is possible for the virus in small respiratory aerosols to travel long distances, up to 10 meters, in closed indoor environments, increasing the risk of airborne transmission (Setti et al., 2020). Air samples collected from hospitals in Wuhan and University of Nebraska Hospital were found to have SARS-CoV-2 RNA present (van Doremalen et al., 2020). Further studies are needed to establish whether it is possible or not to detect SARS-CoV-2 RNA in air samples collected from symptomatic patients' rooms when AGPs or support treatments are not being performed. As an evident, there is no conclusive proof for the airborne transmission of COVID-19 yet. However, the aerosol transmission hypothesis put forward by published and unpublished data requires attention and must be explored. Aerosol and surface stability of SARS-CoV-2 seems to be similar to SARS-CoV, although their epidemiological characteristics are different, which implies 
that these differences likely arise from other factors such as high viral load (particularly in the upper respiratory tract), high infectivity, and asymptomatic transmission (Wei et al., 2020).

\section{Transmissibility and contagiousness}

Evidence suggests that viral shedding can begin a few days before the onset of initial symptoms and occurs at the highest rate in the upper respiratory tract early in the disease, especially during the first three days after the onset of symptoms (He et al., 2020; van Doremalen et al., 2020). The median duration for viral shedding is up to 20 days after the appearance of initial symptoms, but infectivity declines after about the first eight days (Huang et al., 2020; Lauer et al., 2020). The average incubation period for SARS-CoV-2 is 5.2 days but can range between 1-14 days (Bai et al., 2020; Jin et al., 2020; Rothan et al., 2020). As discussed, pre-symptomatic cases can transmit infection, but as far as asymptomatic transmission is concerned, the current evidence is positive but not confirmatory (Day, 2020; He et al., 2020). Symptomatic patients remain the primary source for the transmission of the virus (WHO, 2020d).

In a skilled nursing facility, when testing was carried out, more than $50 \%$ of SARS-CoV-2-positive residents were asymptomatic at the time of testing and likely contributed to virus transmission. Control measures that focused only on symptomatic cases failed to contain the virus, which further fortified the idea that asymptomatic cases can transmit the disease (Arons et al., 2020). The virus can also be shed in the stool of infected persons for a few days; however, whether the stool can serve as a potential source of infection or not still remains uncertain and requires further investigation (Lo et al., 2020).

The Basic Reproduction Number $\left(R_{0}\right)$ is a measure of transmissibility of a virus. According to the $\mathrm{WHO}$, the estimated $R_{0}$, (the average number of secondary cases produced by one infected individual introduced into a population of susceptible individuals (van den Driessche, 2017) for COVID-19 is 1.4-2.5 (Lake, 2020). Other studies have found it to be significantly higher than the WHO estimate. According to one study, it was found to range between 2.24 to 3.58 (Lai et al., 2020). Another study reported it to be around 3.28 (Liu et al., 2020).

However, $\mathrm{R}_{0}$ is not a biological constant and it can be affected by several biological, socio-behavioral and environmental factors that influence the transmission of a pathogen, so this calculation is prone to error, as concluded by the first study (Delamater et al., 2019). The $\mathrm{R}_{0}$ value calculated by WHO may also change as more data become available.

\section{Risk factors, infection progression, and mortality}

The period between the onset of initial symptoms and death usually ranges from 6 to 41 days, with an average of 14 days. The period varies in individual cases and largely depends on the age and immune status of the patient, being shorter among the elderly, immunocompromised, and those with underlying conditions such as hypertension, diabetes, cardiovascular disease, and chronic obstructive pulmonary disease. In these patients, there was a rapid onset of acute respiratory distress syndrome (ARDS), septic shock, metabolic acidosis, coagulation dysfunction, multiple organ failure, and eventual death (Guo et al., 2020; Hatipoğlu, 2020; Li et al., 2020; Rothan and Byrareddy, 2020; Somily and BaHammam, 2020). Even though most of the characteristic laboratory finding includes normal or depleted leucocyte levels, in severe cases, blood urea, creatinine, and D-dimer levels were also found to be significantly elevated (Hatipoğlu, 2020). Some of these laboratory markers, especially the lymphocyte count, may predict the clinical course. However, the relationship between these markers and the disease progression is not yet fully understood (University of Edinburgh, 2020).

Based on the current data, about $80.9 \%$ of patients develop mild to moderate illness, $13.8 \%$ develop severe illness, and $4.7 \%$ of patients were critical. The total death rate to date has been $2.3 \%$ considering all reported cases together. Recovery usually takes two weeks for mild to moderate cases and three to six weeks for severe cases (Jin et al., 2020). These numbers reveal that most patients show a good prognosis, with only the elderly and those with comorbidities being at high risk.

Many case studies conducted in Mainland China have concluded that the complications associated with COVID19 include ARDS, shock, arrhythmia, liver dysfunction, secondary infection, and acute liver and cardiac injury. Disease progression is faster among the elderly, especially those aged 65 or older, and those with comorbidities - the disease severity is related to poor clinical outcomes. Neonates and the elderly, with immature or weak immune systems, need more attention than immunocompetent healthy adults (Guo et al., 2020). However, individual variations do exist and must not be ignored.

\section{Global transmission}

Researchers around the world are working to know more about the virus, and more is being learned every day. Despite these efforts, there are still so many questions that remain unanswered. As of now, COVID-19 has affected 213 countries and two international conveyances around the world. At the time of writing this review (June $7,2020)$, the number of confirmed cases has reached $7,064,230$, with 404,585 deaths, and 3,451,015 recoveries (Worldometer, 2020).

The United States has reported the highest number of confirmed COVID-19 cases globally, followed by SouthEast Asia and Europe (WHO, 2020e). As of June 7, 2020, the total number of confirmed cases in the US was $2,010,622$, with 115,020 deaths. The observed case fatality ratio was highest in Mexico and Iran, with the total number of deaths at 13,511 and 8,281 , respectively. Among European countries, France, Spain, and Romania have respectively witnessed the highest number of deaths per 100,000 population. Indonesia was the worst affected 
of the South-East Asian countries, while India had the highest case fatality rate of the South Asian countries (Johns Hopkins University and Medicine, 2020). In the African region, since the beginning of the outbreak, the highest number of deaths was reported in South Africa, Algeria, and Nigeria (Worldometer, 2020).

\section{Emergence and progression of COVID-19 in the Middle East and other Arab countries}

The latest distribution (updated June 7, 2020) of COVID19 cases in different regions of the Middle East and some Arab countries is summarized in Table 1. On January 27, 2020, the United Arab Emirates (UAE) became the first Middle Eastern country to report a COVID-19 positive case, detected in a four-members family that had recently arrived from Wuhan. Other countries have not been able to escape its effects either, but as per the current data, Qatar is the worst-hit country in the region (based on the number of cases per million population), followed by Bahrain, Kuwait, UAE, and Oman.

In Qatar, the first case was reported on February 29, and 68,790 confirmed cases have been reported to date. However, the total number of deaths is 54 , which signifies that the cases are well managed. Iran has served as the focus of transmission of COVID-19 to other Middle Eastern countries, as evident from the data. Bahrain reported its first case on February 24, 2020, and cases have been on an upward trajectory ever since, with 8,701 cases per million population, making it easily the $2^{\text {nd }}$ worst-hit Middle Eastern country. Kuwait reported its first cases on February 26, among 700 people evacuated from Mashhad, Iran. The total number of deaths has reached 264. The countries that are least affected include Palestine, Jordan, Yemen, and Syria (Worldometer, 2020; Pharmaceutical Technology, 2020).
Extensive countrywide lockdowns and curfews have been implemented in the Middle Eastern countries in an effort to contain the virus (The National, 2020). The magnitude of the problem, however, continues to increase, which highlights the inadequacy of these measures. The current data reveal that the mortality rate is highest in Kuwait, Iran and Turkey (Worldometer, 2020).

Among the Gulf Cooperation Council (GCC) countries, Qatar, Bahrain, Kuwait, and UAE are the worst-affected with the maximum number of cases per million population. Saudi Arabia and Oman have comparatively better dealt with the pandemic. The situation escalated quickly in Qatar; it has the highest number of cases in the Middle East as well as Asia (Worldometer, 2020). Saudi Arabia was the last to report an initial confirmed case, on March 2 (Pharmaceutical Technology, 2020).

All six members of GCC (Saudi Arabia, UAE, Kuwait, Oman, Bahrain and Qatar) have responded aggressively to the COVID-19 outbreak, implementing countrywide closures of restaurants, bars, gyms, and other public places as well as bans on public gatherings (The National, 2020). The overall mortality rate of COVID-19 patients in GCC is relatively low; as of May 18, 2020, the mortality rate was 0.6. (Figure 1) (Alandijany et al., 2020).

Saudi Arabia is the sixth worst-hit country in the Middle East, as well as in the GCC, with a total number of cases at 101,914; up to the date of writing the manuscript (June 7, 2020). It was the last to report a confirmed case among GCC countries on March 2, 2020. COVID-19 was detected in a Saudi citizen who had recently returned from Iran (Worldometer, 2020; Pharmaceutical Technology, 2020).

The total number of cases in Saudi Arabia is 101,914, with 2931 cases per million population and a total number of deaths at 712 to date. The highest number of cases have emerged from Makkah Almukarramah, followed by

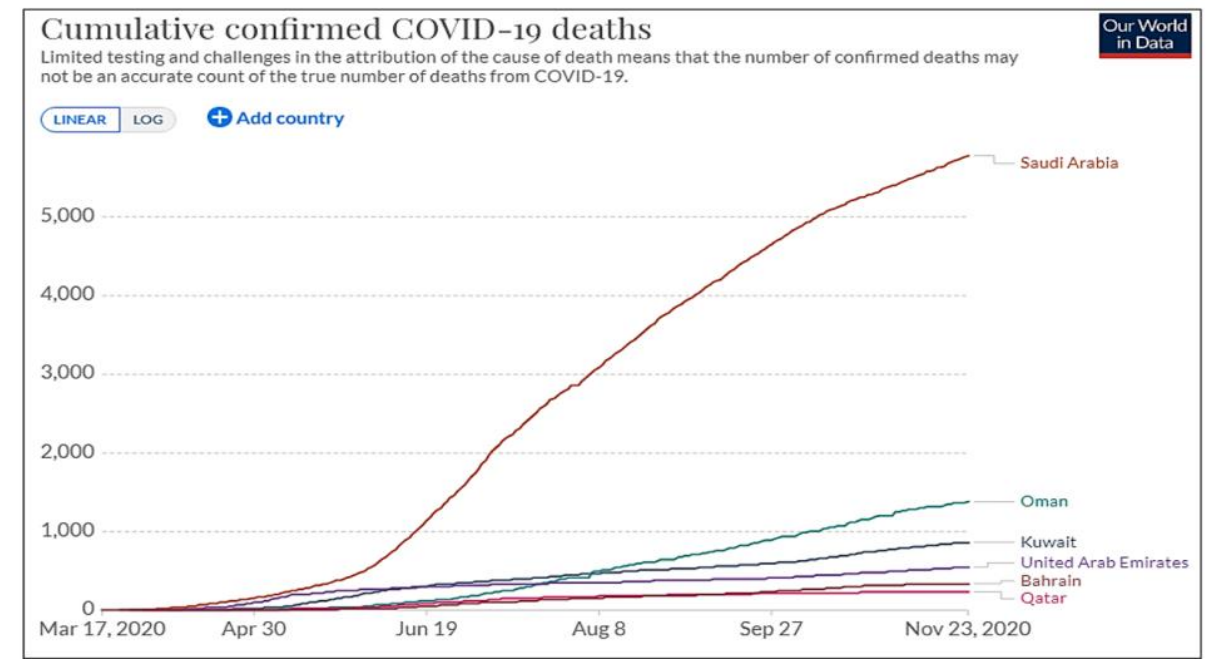

Figure 1: Statistics of COVID-19 causing deaths in Gulf Cooperation Council (GCC) (Source: CDC, 2020). 
Malays. J. Microbiol. Vol 17(2) 2021, pp. 227-243

DOI: http://dx.doi.org/10.21161/mjm.200903

Table 1: Distribution of COVID-19 cases in different regions of the Middle East and some Arab countries- Last updated on $7^{\text {th }}$ June, 2020 (Source: Worldometer, 2020).

\begin{tabular}{|c|c|c|c|c|c|c|c|c|c|}
\hline Country & $\begin{array}{l}1^{\text {st }} \text { confirmed } \\
\text { case reported }\end{array}$ & $\begin{array}{l}\text { Source of } 1^{\text {st }} \text { case } \\
\text { reported }\end{array}$ & $\begin{array}{c}\text { Total } \\
\text { cases/million } \\
\text { population }\end{array}$ & $\begin{array}{l}\text { Total } \\
\text { cases }\end{array}$ & $\begin{array}{c}\text { Total } \\
\text { deaths/million } \\
\text { population }\end{array}$ & $\begin{array}{l}\text { Total } \\
\text { deaths }\end{array}$ & $\begin{array}{l}\text { Total } \\
\text { recovered }\end{array}$ & $\begin{array}{c}\text { Total } \\
\text { test/million } \\
\text { population }\end{array}$ & Total test \\
\hline Qatar & February 29 & Iran & 24,500 & 68,790 & 19 & 54 & 44,338 & 91,008 & 255,533 \\
\hline Bahrain & February 24 & Iran & 8,701 & 14,763 & 15 & 25 & 9,468 & 216,328 & 367,056 \\
\hline Kuwait & February 26 & Iran & 7,465 & 31,848 & 62 & 264 & 20,205 & 73,904 & 315,285 \\
\hline UAE & January 29 & Wuhan & 3,927 & 38,808 & 28 & 276 & 21,806 & 252,981 & $2,500,000$ \\
\hline Oman & February 24 & Iran & 3,312 & 16,882 & 15 & 75 & 3,451 & 21,323 & 108,679 \\
\hline $\begin{array}{l}\text { Saudi } \\
\text { Arabia }\end{array}$ & March 2 & Iran & 2,931 & 101,914 & 20 & 712 & 72,817 & 27,555 & 958,237 \\
\hline Iran & February 19 & - & 2,047 & 171,789 & 99 & 8,281 & 134,349 & 12,928 & $1,084,857$ \\
\hline Turkey & March 11 & Europe & 2,019 & 170,132 & 56 & 4,692 & 137,969 & 27,749 & $2,338,593$ \\
\hline Israel & February 21 & $\begin{array}{l}\text { Diamond Princess } \\
\text { Cruise Ship }\end{array}$ & 1,942 & 17,863 & 32 & 298 & 15,091 & 70,612 & 649,463 \\
\hline Egypt & February 14 & China & 333 & 34,079 & 12 & 1,237 & 8,961 & 1,321 & 135,000 \\
\hline Iraq & February 24 & Iran & 308 & 12,366 & 9 & 346 & 5,186 & 7,547 & 303,053 \\
\hline Lebanon & February 22 & Iran & 195 & 1,331 & 4 & 30 & 768 & 13,937 & 95,154 \\
\hline Palestine & March 5 & Greece & 93 & 472 & 0.6 & 3 & 403 & 8,812 & 44,876 \\
\hline Jordan & March 2 & Italy & 79 & 808 & 0.9 & 9 & 607 & 21,785 & 222,128 \\
\hline Yemen & April 10 & - & 16 & 484 & 4 & 112 & 23 & 4 & 120 \\
\hline Syria & March 22 & - & 7 & 125 & 0.3 & 6 & 58 & - & - \\
\hline
\end{tabular}




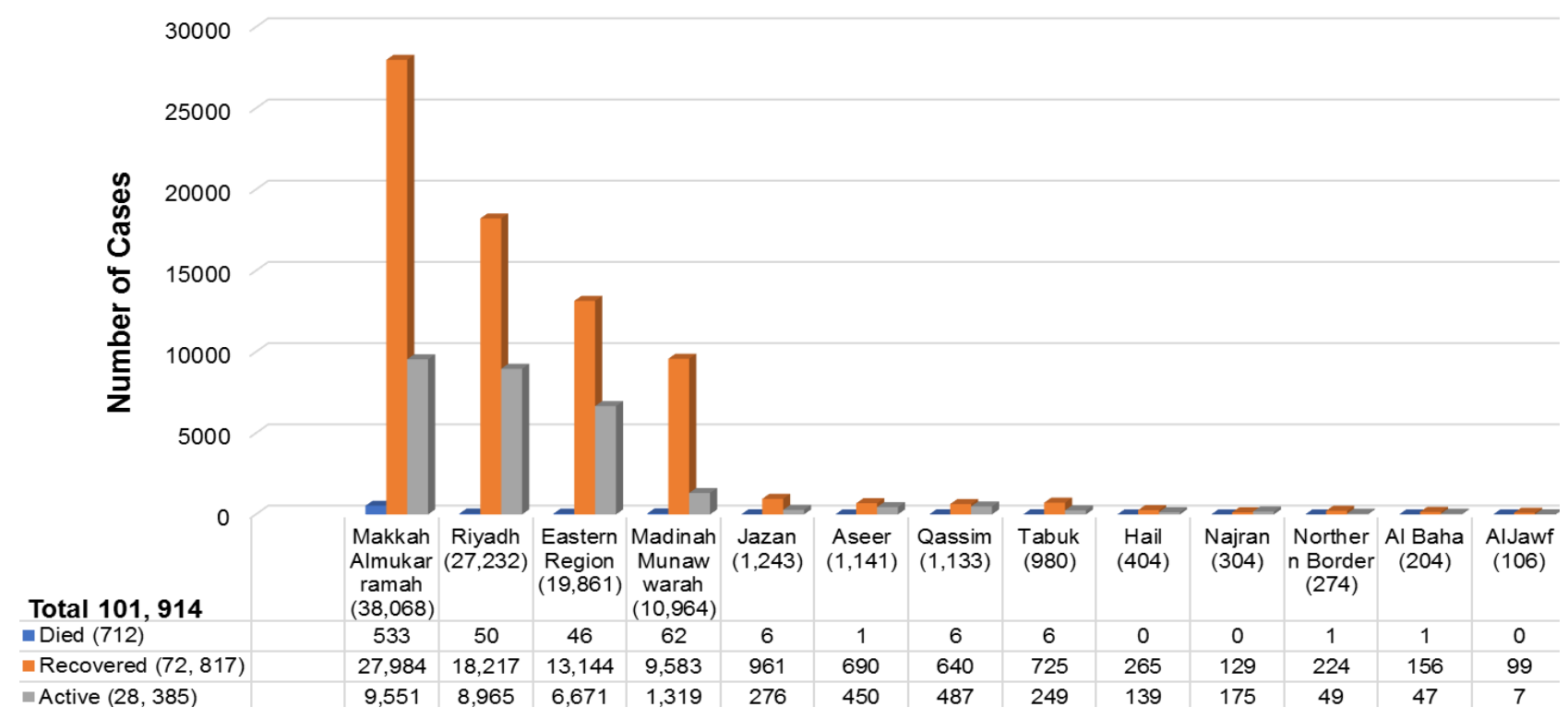

Figure 2: The distribution of COVID-19 cases in different regions of Saudi Arabia from the first reported case until June 7, 2020. (Source: COVID-19 Dashboard: Saudi Arabia, 2020).

Riyadh, the Eastern region, and Madinah Almunawwarah (Figure 2). Nearly $75 \%(533 / 712)$ of the total deaths have been reported from Makkah Almukarramah region (Worldometer, 2020; Pharmaceutical Technology, 2020). The emergence of the highest number of cases and the total number of deaths from Makkah Almukarramah can be attributed to the crowded slums in the city, the labor camps, and the large number of undocumented immigrants that the city hosts. Owing to a lack of awareness, residents of these slums do not visit the hospital until the condition becomes critical, often leading to mortality. The fear of high healthcare costs is another contributing factor, despite the initiative of the Saudi government that encompasses free treatment for anyone infected with COVID-19, without any discrimination, as a part of their pandemic containment efforts. Riyadh, a city three times larger than Makkah, has the second-highest number of COVID-19 cases. This capital city with a diverse and dense population have contributed to the high number of COVID-19 cases and, subsequently, the deaths reported in the region (The Economic Times, 2020).

In the Eastern Region, travelling to Iran is the main reason for the spread of COVID-19. An annual visit to Iran for religious purposes is a norm for some residents of the area. As it is known, Iran was a hotspot for the spread of the virus at the beginning of the pandemic, serving as a source of transmission of infection to Eastern Province and subsequently, the rest of the country. As of now, 19,861 confirmed cases of coronavirus have been reported from the region with the total number of deaths is 46 (The Guardian, 2020).
In addition to the free treatment for those infected with COVID-19, several other measures have been put in place in order to halt the further progression of SARSCoV-2 in Saudi Arabia, the most notable being the suspension of Umrah. It has also suspended its recently introduced e-visa program imposing travel restrictions. Despite the substantial economic impact, it will have in Saudi Arabia, its efforts to stem COVID-19 are beneficial for GCC and other Middle Eastern countries (Ebrahim and Memish, 2020). Owing to its prior experience with the MERS outbreak in 2012, Saudi Arabia was quicker to impose restrictions on the social gathering, travelling, and business activities (Yezli and Khan, 2020), leading to a flatter curve compared to other GCC countries, and remaining second only to Oman when it comes to the least number of cases (Worldometer, 2020).

The distribution of COVID-19 cases in the different regions of Saudi Arabia from the first reported case until June 7, 2020 is shown in Figure 2.

\section{Clinical findings}

The clinical findings in COVID-19 patients are similar to those found in SARS-CoV and MERS-CoV, including but not limited to fever, cough, fatigue, headache, diarrhea, myalgia, dyspnea, hemoptysis, normal or sometimes decreased leucocyte count, and pneumonia confirmed by radiography. However, the most common symptoms are fever, cough, and fatigue. Despite the similarities with SARS-CoV and MERS-CoV, there are a few features unique to SARS-CoV-2, including the involvement of the lower respiratory tract, characterized by symptoms like sore throat, sneezing, and rhinorrhea (Rothan and 
Malays. J. Microbiol. Vol 17(2) 2021, pp. 227-243

DOI: http://dx.doi.org/10.21161/mjm.200903

Table 2: Summary of all stages of the infection and treatment.

\begin{tabular}{|c|c|c|c|}
\hline & \multirow{2}{*}{$\begin{array}{l}\text { Stage I } \\
\text { (Mild respiratory } \\
\text { illness) }\end{array}$} & $\begin{array}{c}\text { Stage II } \\
\text { (Pulmonary involvement) }\end{array}$ & \multirow{2}{*}{$\begin{array}{c}\text { Stage III } \\
\text { (Hyperinflammation) }\end{array}$} \\
\hline & & $\begin{array}{l}\text { (a) without } \\
\text { hypoxia }\end{array}$ & \\
\hline $\begin{array}{l}\text { Severity of } \\
\text { illness }\end{array}$ & High viral response & $\begin{array}{l}\text { The viral response starts to decrease, } \\
\text { and host inflammatory response begins } \\
\text { to appear, increasing over time }\end{array}$ & $\begin{array}{l}\text { The inflammatory response is } \\
\text { very high; viral response has } \\
\text { completely disappeared. }\end{array}$ \\
\hline Symptoms & $\begin{array}{l}\text { Mild, non-specific } \\
\text { symptoms: } \\
\text {-Fever > 99.6 }{ }^{\circ} \mathrm{F} \\
\text {-Headache } \\
\text {-Dry cough } \\
\text {-Diarrhea }\end{array}$ & $\begin{array}{l}\text {-Respiratory discomfort } \\
\text { - } \mathrm{Hypoxia}\left(\mathrm{PaO}_{2} / \mathrm{FiO}_{2} \leq 300 \mathrm{mmHg}\right)\end{array}$ & $\begin{array}{l}\text {-ARDS } \\
\text {-Shock } \\
\text {-Heart Failure }\end{array}$ \\
\hline Signs & $\begin{array}{l}\text { Lymphopenia, } \\
\text { Increased } \\
\text { prothrombin time, } \\
\text { elevated D-dimer } \\
\text { and LDH }\end{array}$ & $\begin{array}{l}\text { Abnormal chest radiograph, normal to } \\
\text { low procalcitonin, transaminits }\end{array}$ & $\begin{array}{l}\text { Elevated inflammatory markers } \\
\text { such as CRP, IL-6, D-dimer, } \\
\text { LDH, Ferritin, Troponin, etc. }\end{array}$ \\
\hline
\end{tabular}

Remdesivir, choloroquine, hydroxycholoroquine, convalescent plasma transfusion

Treatment

Give antiviral, reduce immunosuppression
Give antiviral, reduce immunosuppression
Mechanical ventilation, corticosteroids
Corticosteroids,

human immunoglobulin, IL-6 inhibitors, IL-2 inhibitors, JAK inhibitors
Byrareddy, 2020; Jin et al., 2020). In addition to respiratory symptoms, patients have exhibited the involvement of multiple organs manifesting as diarrhea, kidney failure, acute liver, and acute cardiac injury (Jin et al., 2020). ACE2, the receptor for SARS-CoV-2, is widely expressed in the respiratory tract as well as the esophagus, stomach, ileum, kidney, bladder, and heart, implying the vulnerability of these organs to the virus. Recently, testicular involvement has also been proposed, leading to concerns regarding fertility, especially in young patients (Fan et al., 2020).

It has been found that disease progression occurs in three stages, the recognition of which is vital for investigation and using targeted therapy (Siddiqi and Mehra, 2020). These three stages of the infection and potential therapies are summarized in Table 2.

\section{Stage I- Mild illness}

Stage I of the illness is encountered around the time of infection and during the incubation period. It is characterized by mild, non-specific symptoms such as fever, malaise, and dry cough. Additionally, anosmia and dysgeusia are frequently reported as early symptoms, occurring before the onset of respiratory symptoms. However, these are short-lived and resolve spontaneously (Bagheri et al., 2020; Gelardi et al., 2020). There is a rapid multiplication of SARS-CoV-2 during this stage, primarily in the respiratory tract. The treatment is mostly symptomatic, as the main anomalies noticed at this stage are neutrophilia and lymphopenia without any other significant abnormality (Siddiqi and Mehra, 2020).

\section{Stage II- Moderate illness}

In the second stage of disease progression, pulmonary involvement is well-established. The symptoms of viral pneumonia, such as fever, cough, and sometimes hypoxia (defined as a partial pressure of oxygen/fraction of inspired oxygen $\left[\mathrm{PaO}_{2} / \mathrm{FiO}_{2}\right]$ of $<300 \mathrm{mmHg}$ ), are present. Upon investigation with diagnostic radiology tools such as X-ray and CT scan, ground-glass opacities or bilateral infiltrates can be seen. In addition, systemic inflammation markers may also be raised but usually not to a remarkable extent.

In many cases, stage II illness requires hospitalization for close monitoring and management. Owing to a lack of specific treatment, the treatment mainly comprises supportive measures. Early in stage II, when hypoxia is not marked, corticosteroid use can be avoidable. However, if the condition of the patient deteriorates and hypoxia becomes pronounced, the patient will likely 
require mechanical ventilation. In such situation, the use of anti-inflammatory drugs such as corticosteroids may be beneficial. Therefore, it is possible to subdivide stage II illness into Stage Ila (viral pneumonia without hypoxia) and Stage Ilb (viral pneumonia with hypoxia) (Siddiqi and Mehra, 2020).

\section{Stage III- Severe illness}

As discussed earlier, a large proportion of COVID-19 cases present with mild illness. Only a small proportion progresses to severe illness, stage III of the disease. In addition to pulmonary signs and symptoms, systemic involvement becomes manifest. In this stage, systemic hyper-inflammation syndrome sets in, evidenced by remarkably elevated markers of systemic inflammation. Moreover, as the disease progresses, shock, respiratory failure, vasoplegia, and cardiovascular collapse can be expected. Extra-pulmonary organ involvement becomes pronounced at this stage. The treatment during this stage is mainly dependent upon immunomodulatory agents such as corticosteroids in conjunction with cytokine inhibitors in order to contain systemic hyper-inflammation before it leads to multisystem organ failure (Siddiqi and Mehra; 2020)

\section{Diagnosis}

The diagnosis of COVID-19 can be based on clinical findings and epidemiological history. In addition, supplementary examinations such as viral RNA detection, CT scan, enzyme-linked immunosorbent assay (ELISA), immune identification technology, and blood culture are extensively used to confirm the diagnosis. Owing to the highly atypical symptoms associated with COVID-19, auxiliary diagnostic tests are recommended ( $\mathrm{Li}$ et al., 2020).

\section{Molecular detection tests}

Among the numerous testing techniques available, nucleic acid detection tests are the most commonly used. Of these, the preferred testing method for the detection of viral RNA is the real-time reverse transcription-PCR (RT$\mathrm{PCR}$ ). Moreover, quantitative polymerase chain reactions (RT-qPCR) and high-throughput sequencing are also used. However, only RT-qPCR is commonly performed, as the application of high-throughput sequencing is limited by its high cost and requirement for specialized instruments (Jin et al., 2020; Li et al., 2020).

Patients with COVID-19 demonstrate a high viral load in both their upper and lower respiratory tracts within 5 to 6 days of the onset of symptoms. A nasopharyngeal and/or oropharyngeal swab is recommended for the screening and diagnosis of infection. However, a single nasopharyngeal swab has become the preferred method, as it is better tolerated by the patient and is also safer for the operator (Tang et al., 2020).

Most of the molecular diagnostics are being developed and used employ RT-PCR. Moreover, other molecular diagnostics are also being developed and evaluated around the world, including loop-mediated isothermal amplification, multiplex isothermal amplification followed by microassay detection, and clustered regularly interspaced short palindromic repeats (CRISPR)-based assays.

\section{Molecular targets for RT-PCR}

Several molecular targets can be employed for coronavirus PCR assays, including genes encoding structural proteins such as envelope glycoprotein spike $(\mathrm{S})$, envelope $(\mathrm{E})$, transmembrane $(\mathrm{M})$, helicase (Hel), and nucleocapsid (N). Additionally, species-specific accessory genes are required for viral replication, including RNA-dependent RNA-polymerase (RdRp), hemagglutinin-esterase $(\mathrm{HE})$, and open-reading frame 1a (ORF1a); ORF1b can also be employed.

The WHO recommends first-line screening with an Egene assay, followed by a confirmatory assay using the RdRp gene. Alternatively, the Centers for Disease Control and Prevention (CDC) in United States recommend using two nucleocapsid protein targets (N1 and N2). To avoid potential cross-contamination with other endemic coronaviruses, as well as the possible genetic drift of SARS-CoV-2, it is recommended to include at least two molecular targets in the assay. In a study conducted in Hong Kong, China, two targets for RT-PCR were used, the first being an nucleocapsid (N) for screening, followed by confirmation using the ORF1b. Likewise, in Germany, E gene and RdRp gene were selected as the molecular targets. In United States, if both the targets in the CDC assay, namely $\mathrm{N} 1$ and $\mathrm{N} 2$, tested positive, the case is considered to be laboratory confirmed. In China, for the assays with three targets, positive results for any two or more targets indicate a laboratory-confirmed case (Tang et al., 2020).

\section{The limitations of $R T-P C R$}

After nasopharyngeal and/or oropharyngeal swab is collected, the samples should be appropriately stored in the viral transport medium and rapidly transported to the microbiology lab, ideally under refrigerated conditions. It is important to note that at times, the samples obtained during the early stages of infection are not able to detect the virus. When retesting is done during the later stages, the site of replication may have shifted to the lower respiratory tract. It is, therefore, recommended to either go for repeated testing or obtain lower respiratory tract specimens. Moreover, safety is an important concern. The processing of respiratory specimens should be carried out in a class-II biological safety cabinet (Tang et al., 2020).

\section{The limitations of $R T-q P C R$}

The sensitivity of RT-qPCR varies from $50 \%$ to $79 \%$ depending upon the protocol used, the number of specimens collected, and the sample type. Some other 
limitations of RT-qPCR include the biohazard associated with the sample and the long waiting time for the results, implying the need for the development of a faster yet cost-effective testing technique (Li et al., 2020).

As of now, many SARS-CoV-2 nucleic acid detection kits have been developed. However, false-negative results remain the primary concern regarding their use. To counter this problem, many improved rapid viral nucleic acid detection tests are being developed. Nose swabs seem to be better than throat swabs, especially for the detection of mild viral load. After the progression of the disease to pneumonia, endotracheal secretions serve as the superior method for the detection of virus, as throat swabs stop being positive in more than $40 \%$ of cases (Templeton, 2020).

Lu et al. (2014) reported that two rRT-PCR assays were developed in the Middle East to target the MERSCoV nucleocapsid $(\mathrm{N})$ gene. These two assays were evaluated using a previously published assay and targeted the upstream region of the envelope gene (upE) in MERS-CoV to detect and confirm MERS-CoV infection. The assay was distributed to international public health partners in affected regions of the Middle East. The design and validation strategy was directed by various principles. The designed upE signature was retained because of its successful and extensive application in the surveillance of MERS-CoV to target the MERS-CoV $1 \mathrm{~b}$ open reading frame (ORF), which is as sensitive as upE (Lu et al., 2014).

Kakhki et al. (2020) reported the ORF8 gene to be a novel target that has proven to be effective in the Middle East. ORF8 contains many regions specific for SARSCoV-2; thus, it is appropriate for probing and primer design. This gene also has regions similar to those in the Bat-SARS coronaviruses (MG772933.1 and MG772934.1) and can be differentiated from other coronaviruses by applying the K_COV-P1 probe (Kakhki et al., 2020).

Corman et al. (2020) states that the WHO recommends the RdRP, $\mathrm{N}$, and $\mathrm{E}$ genes be used to detect SARS-CoV-2 (Corman et al., 2020). In general, the $\mathrm{RdRp}$ gene is proposed for use in a confirmatory assay, the $\mathrm{N}$ gene for extra confirmation, and the $\mathrm{E}$ gene for firstline screening. These genes are promising targets for detecting coronavirus. The reasoning behind these assays is that SARS-CoV- 2 is a betacoronavirus ( $\beta-C o V)$, which is structurally identical to other coronaviruses from the Coronaviridae family, which includes MERS-CoV and SARS-CoV (Afzal, 2020).

\section{CRISPR/Cas13- technology}

Recently, a CRISPR/Cas13-based SHERLOCK technology that was previously used for the detection of Zika virus (ZIKV) and dengue virus (DENV) has been released for SARS-CoV-2. However, this test remains unverified in clinical use, as it has not been used on samples from COVID-19 patients (Jin et al., 2020).

\section{Serological tests}

Owing to the acute serological responses associated with COVID-19, relevant tests have been developed using appropriate reagents (Jin et al., 2020). Serology has demonstrated its usefulness during SARS and other coronavirus outbreaks. It measures the host's response to the infection and serves as an indirect measure of infection that is best utilized retrospectively, which is useful in finding evidence of a prior COVID-19 infection.

For the rapid detection of SARS-CoV-2 antigens and antibodies, immunoassays have been developed. Typically, these rapid detection point-of-care assays are lateral-flow assays. While these lateral-flow assays provide the advantages of rapid detection and lower cost, they are also susceptible to poor sensitivity during the early stages of infection. Since the viral load is variable among patients, the risk of cases being missed due to poor antigen detectability and/or sampling variability persists (Tang et al., 2020).

In addition, the rapid lateral-flow assay for the detection of both $\lg M$ and $\lg G$ antibodies is expected to play an important role during the ongoing outbreak by allowing the determination of the burden of infection, the role of asymptomatic infections, the basic reproduction number, and the overall mortality associated with the disease. Given the non-specific nature of IgM responses, serology is not expected to play a role in the management of active cases. However, it can be used to diagnose late COVID-19 cases and determine the immune status of healthcare professionals working amidst the outbreak (Tang et al., 2020).

Viral culturing is not recommended for the diagnosis of COVID-19 (Tang et al., 2020). This is because viral contamination is a serious possibility and because SARSCoV-2 is difficult to detect, and there is a deficiency of effective approaches to treat infected cell cultures. Moreover, few viruses can cause morphological variations within infected cell colonies (e.g. cytopathic effects) that are detectable by a microscope. Viral contaminations can also cause integration of the viral genome by modifying the morphology of cells. The production of viral colonies from these cell lines is highly hazardous for other cell cultures in research labs owning to cross-contamination; it is also hazardous to laboratory workers because of the possibility of infection. Virus-free cell cultures must be maintained for clinical industrial research and development by preventing such contamination. These cell culture contamination events can occur due to preexisting primary cultures, contaminated raw materials, and through cell passaging (Merten, 2002).

\section{Imaging techniques}

In clinical settings, a chest radiograph or CT remains an essential tool for the detection of COVID-19. The findings continue to be similar in most positive cases, characterized by bilateral consolidative opacities, shadows, and parenchymal ground-glass appearance, as discussed earlier. A promising aspect of using CT is the 
employment of artificial intelligence (Al) for correct interpretation of images leading to a significant improvement in the establishment of correct diagnosis. In addition, the false-negative results associated with RTqPCR emphasize the need for an auxiliary diagnostic method.

Especially for patients with a negative RT-qPCR and high clinical suspicion of COVID-19, repeated RT-qPCR combined with chest CT can help reach a conclusive diagnosis. Additionally, high-resolution computed tomography (HRCT) can help establish an earlier diagnosis and evaluate the severity of the disease. Even though the CT scan adds excellent diagnostic value, it also has its limitations, such as its inability to distinguish between different forms of viral pneumonia (Jin et al., 2020; Li et al., 2020).

\section{Limitations of current diagnostic techniques}

The limitations of both RT-qPCR and CT scan highlight the need for the development of another technique, such as immunological detection of viral antigens or host antibodies. Even though point-of-care testing (POCT) technology for $\operatorname{lgM} / \operatorname{lgG}$ has been developed, it is not being clinically used, hence no data are available regarding its efficacy ( $\mathrm{Li}$ et al., 2020). The need for the development of a more sensitive, rapid, and cost-effective test continues to persist. Currently used modalities to diagnose COVID-19 are summarized in (Table 3).

\section{Treatment}

Currently, there are no specific anti-viral drugs or vaccination available for the treatment and control of COVID-19. Supportive treatment remains to be the mainstay of COVID-19 patient management (Jin et al., 2020). This includes oxygen therapy, conservation fluid management, and the use of broad-spectrum antibiotics to prevent secondary bacterial infections ( $\mathrm{Li}$ et al., 2020). Based on the molecular mechanism of coronavirus infection and the genetic makeup of SARS-CoV-2, several treatment modalities are being investigated for their potential to be remodeled for the effective treatment of this novel coronavirus.

\section{Type 1 interferons}

Type 1 interferons exert an anti-viral action by inducing the formation of a broad range of proteins involved in the impairment of viral replication in the target cells; previous studies in this regard done on the SARS-CoV report IFN$\beta$ to be more effective than IFN- $\alpha$. The effect can be potentially fortified by combination with an anti-viral agent such as ribavirin (Jin et al., 2020).

\section{Antiviral Agents}

Lopinavir, Ritonavir and Ribavirin in combination: A combination of lopinavir and ritonavir, extensively used in the treatment of human immunodeficiency virus (HIV), when combined with ribavirin, has shown promising therapeutic effects for SARS and MERS. These anti-HIV drugs have been recommended for the treatment of COVID-19. A combination of danoprevir and ritonavir has also shown some positive results and is currently undergoing phase I clinical trials (Jin et al., 2020; Li et al., 2020).

Ribavirin: During the 2002 SARS outbreak in Hong Kong, ribavirin with or without combination of a steroid was extensively used. IFN- $\beta$ in combination with ribavirin was found to potentially inhibit the SARS-CoV replications, providing hope that the results can be extended to SARS-CoV-2 (Jin et al., 2020; Li et al., 2020).

Remedisivir: Remedisivir has also been used in the treatment of SARS-CoV. It is an adenosine analogue that targets RNA- dependent RNA polymerase, blocking viral replication. When combined with IFN- $\beta$, the therapeutic effect seems to be superior to that of lopinavir/ritonavir and IFN- $\beta$ combination for the treatment of MERS-CoV. Remedesivir was administered intravenously by the Washington Department of Health for the treatment of first COVID-19 patient in the United States, and it seemed to have anti-viral effects against the SARS-CoV-2. However, further studies are needed to establish its safety and efficacy for the treatment of COVID-19. It is currently undergoing phase III clinical trials and has been approved for emergency use by the US FDA. Japan's health ministry has also approved it for the treatment of COVID-19 (Jin et al., 2020; Li et al., 2020).

Nelfinavir. Nelfinavir has also been tested for SARSCoV and considering its therapeutic effects it may potentially have applications for SARS-CoV-2 as well (Jin et al., 2020; Li et al., 2020).

Arbidol: Arbidol, a broad spectrum anti-viral compound, has been tested for the treatment of both SARS-CoV and SARS-CoV-2. It has been found to have anti-viral effects against SARS-CoV-2 and is recommended for clinical treatment (Jin et al., 2020; Li et al., 2020).

\section{Agents targeting coronaviral proteins}

In addition, therapies that target specific functional coronaviral proteins such as papain-like proteinase (PLP) and Coronavirus main proteinase (3CLPro), which are involved in viral replication and suppression of host immunity, present promising options. For example, cinanserin and flavonoids for 3CLPro and diarylheptanoids for PLP can be good options (Li et al., 2020). Because viral entry into the cells is mediated by Angiotensin-converting enzyme 2 (ACE2), the agents that can potentially block the interaction between the viral $S$ protein and ACE2 can bring about desirable results. Renin-angiotensin system (RAS) inhibitors, such as ACE1 and Angiotensin II type I receptor (AT1R), can be helpful in this regard (Jin et al., 2020). EIDD-2801, a novel oral anti-viral drug, is currently undergoing phase I clinical trials and has been demonstrated to be useful against SARS and MERS (STAT News, 2020). 
Malays. J. Microbiol. Vol 17(2) 2021, pp. 227-243

DOI: http://dx.doi.org/10.21161/mjm.200903

Table 3: Currently used modalities to diagnose COVID-19.

Diagnostic method Characteristics

Molecular detection test (RT-PCR/ RT-qPCR)

Serological tests

(SARS-CoV-2 antigens and antibodies)

Imaging Techniques

(Chest X-Ray/ CT)
Most commonly used method to detect SARS-CoV-2, but expensive and requires a complex protocol.

Rapid and cost-effective tests but have poor sensitivity in early infection.

Very useful in clinical settings, most positive cases are characterized by bilateral consolidative opacities, shadows, and parenchymal ground-glass appearance.

\section{Chloroquine}

Chloroquine was developed against malarial infection in 1934. The analog of chloroquine is hydroxychloroquine, which was industrially synthesized in 1946. In addition to malaria, hydroxychloroquine is used to treat autoimmune diseases, such as rheumatoid arthritis and systemic lupus erythematosus. Compared with chloroquine, hydroxychloroquine generally has less severe side effects and drug-drug interactions, in addition to a low propensity to prolong intervals. Both hydroxychloroquine and chloroquine enhance the endosomal $\mathrm{pH}$ and inhibit fusion between the host cell membrane and SARS-CoV-2. Chloroquine is an inhibitor of the cellular angiotensinconverting enzyme glycosylation-related receptor and, thus, might restrict the binding of SARS-CoV-2 (Fiolet et al., 2020). In vitro studies have found that both hydroxychloroquine and chloroquine can block SARSCoV-2 transport from early endosomes to endolysosomes, probably preventing discharge of the viral genome. The two compounds also have immunomodulatory effects, which have been thought to be potential modes of action to treat COVID-19. However, although hydroxychloroquine demonstrated antiviral activity in vitro, hydroxychloroquine in the presence or absence of azithromycin did not decrease lower or upper respiratory tract viral burden or show clinical effectiveness in a rhesus macaque model (Kashour et al., 2020).

The potential use of chloroquine for the treatment of COVID-19 has recently stirred significant controversy. In SARS-CoV, it has been found to interfere with viralreceptor interaction, leading to a protective effect. Currently, it is approved and recommended for the containment of COVID-19 by Chloroquine, when combined with remedisivir, is effective in inhibiting SARSCoV-2 in vitro (Jin et al., 2020; Li et al., 2020).

\section{Convalescent plasma and antibody treatment}

Convalescent plasma and antibody treatment are also being investigated as potential therapeutic options. During preliminary trials, plasma from convalescent patients administered to acutely and severely ill patients resulted in positive outcomes. Moreover, using a recombinant human monoclonal antibody (mAb) can neutralize the viral load serving as an effective yet straightforward treatment modality. Several coronavirus-specific human monoclonal antibodies such as CR3022, m396, and CR3014 could possibly serve as therapeutic agents. Their effects are mediated by their attachment to the receptor binding domain (RBD) of SARS-CoV-2 (Li et al., 2020). Gimsilumab is also important in this regard and is currently in phase II clinical trials. However, there are certain limitations to the use of mAbs, as they can only recognize a specific epitope and require a particular time to be developed. Some pharmaceutical companies are attempting to produce polyclonal antibodies to extend the benefits; SAB-185 is an outstanding example (Gelardi et al., 2020)

\section{Systemic anti-inflammatory drugs}

Using systemic anti-inflammatory drugs can help reduce the cytokine storm, protecting the patient against inflammation-induced damage (Jin et al., 2020). An antibody against the protein GM-CSF, an important inflammatory cytokine, is currently being tested in humans (Gelardi et al., 2020)

\section{Stem cell-based}

Currently undergoing phase II clinical trials, a stem cellbased treatment modality called MultiStem is rendered safe for the management of ARDS. It uses a specific type of stem cells harvested from the patient's bone marrow. Its efficacy, however, remains unknown (Gelardi et al., 2020).

Another novel treatment option that uses stem cells to generate natural killer cells is currently under development and was approved on April 2 by the US FDA to begin a phase I clinical trial. Many other preclinical 
studies are also currently under progress (Gelardi et al., 2020).

\section{SARS-CoV-2 vaccines}

The development of effective SARS-CoV-2 vaccines is vital for the reduction of cases, transmission, viral shedding, disease severity, and mortality. The WHO is conducting an extensive number of clinical trials to test potential treatments for COVID-19. In addition, tens of institutes around the world have been attempting to develop a vaccine ever since the genome of SARS-CoV-2 was sequenced.

The Coalition for Epidemic Preparedness, an epidemic response group, and Gavi, a vaccine alliance of governments and organizations, are working in collaboration with the WHO to discover a COVID-19 vaccine. At present, 94 countries have signed the worldwide vaccine plan, known as COVAX, which aims to develop a vaccine for COVID-19 by the end of 2020 . COVAX also has a fund of $£ 1.52$ billion ( $\$ 2$ billion) to support the purchase and fair distribution of the vaccine across the globe. Other scientific institutes and groups who are working in a similar discovery capacity include Oxford University, AstraZeneca, Moderna, PfizerBioNTech, and Gamaleya (BBC News, 2020).

Structural components of the virus, especially mRNA, the RBD component of the S protein, and epitopes, are being investigated in this regard (Templeton, 2020; STAT News, 2020). Moreover, many SARS-CoV-2 vaccines such as mRNA-1273 are already undergoing clinical trials to establish their safety and efficacy (STAT News, 2020).

$m R N A-1273$

mRNA-1273, being developed by a pharmaceutical company, has completed its clinical phase I trial, and phase II studies have been approved by the FDA and will begin shortly. This vaccine is a synthetic mRNA encoding a SARS-CoV-2 surface protein in order to stimulate an immune response (STAT News, 2020).

\section{Other approaches}

Several other approaches are also currently under testing for the development of a vaccine. One of the approaches involves taking a snippet from the coronaviral genome and entwining it with a harmless virus that will be used to infect healthy subjects to test its efficacy.

A DNA vaccine is also reportedly under trial that would be capable of generating protective antibodies using an engineered, harmless, and inactive version of SARSCoV-2. This vaccine uses the genetic sequence encoding the coronavirus surface protein to generate mRNA. This vaccine type is thought to be effective for use in most human populations (STAT News, 2020).

\section{Next-generation vaccines}

As the next-generation platforms are not licensed for use in humans except for Dengvaxia and Ervebo, which are viral vector-based vaccines. The ability to produce nextgeneration vaccines rapidly and on a large scale is unclear at present. Although manufacturing capability for vaccines exists for the classical platforms using the prevailing infrastructure, regular vaccine manufacturing could be reduced. Maintaining the vaccination capacity for preventable infections while simultaneously producing millions of SARS-CoV-2 vaccine doses will be crucial for global healthcare. In addition to the vaccine antigen itself, the necessary delivery or adjuvant molecules and, in the case of DNA vaccines, exceptional distribution strategies, must also be addressed on a mass scale. Millions of dosages are required to be prepared and distributed, which will be a practical challenge. Furthermore, with the potential exclusion of DNA vaccines, all other vaccine types will likely require cold chain distribution (van Riel and de Wit, 2020).

\section{Infection control measures}

In the absence of an approved treatment or prevention option, the best way to deal with this pandemic is to break the chain of person-to-person transmission. Although the SARS-CoV-2 shows high infectivity, it is less virulent than SARS-CoV and MERS-CoV, as evident by its low morbidity and mortality rate.

On a personal level, the $\mathrm{WHO}$ and US CDC continue to recommend droplet and contact precautions such as masks, gloves, and hand-sanitizers for those caring for a person with COVID-19 infection or at risk of infection. For conditions where arterial blood gas (ABGs) are being performed, airborne precaution and the use of personal protective equipment (PPE) is recommended (WHO, 2020c).

On a public level, extensive preventive interventions must be undertaken. Currently, many countries around the world are in a state of lockdown to control the transmission of the virus. Tests are being conducted and suspected and confirmed cases are being isolated. Special attention must be paid to particularly high-risk groups such as the elderly, children, and healthcare providers. Public health departments should ensure the strict implementation of lockdown measures and observation of quarantines. Public availability of decontaminating agents such as hand sanitizers should also be ensured. When launching and implementing preventive measures, certain aspects such as subclinical infections, potential although not yet proven (for example, fecal-oral) routes of transmission, and animals that may be serving as reservoirs or intermediate hosts, should be taken into account as well. 


\section{CONCLUSION}

Pandemics constitute a massive challenge to public healthcare organizations and global financial security. Due to modern scientific progress that has increased human-animal integrations, this novel coronavirus will likely continue to hinder our overall quality of life. Acquiring the insights into all aspects of COVID-19 is crucial to apply appropriate measures that will support the prevention of such pandemics or lessen their influence on human societies when they inevitably take place. Primary emphasis must be placed on the symptoms and pathophysiology of COVID-19 and on generating efficient vaccinations and drug treatments. Our ability to manage future outbreaks will depend upon the actions we take based on the knowledge of such a destructive pandemic. We hope that the speedy exploration of the present COVID-19 pandemic will assist in delivering innovative ways to address this crisis.

The ongoing COVID-19 pandemic has become a global health issue, challenging medical infrastructure around the world. While most of the cases are resolved spontaneously, the ones leading to complications such as pneumonia and ARDS are proving to be enough to overburden healthcare systems. The primary modes of transmission include respiratory droplet and contact infection. Currently, the most commonly used molecular technique to detect the virus is QRT-PCR (Quantitative Real Time or Reverse Transcriptase Polymerase Chain Reaction), which has its own limitations. In the absence of an effective treatment regimen, prevention, control, and supportive treatment for those infected should be emphasized.

Despite much research about COVID-19 since its outbreak, there are still many unknown questions, and the answer to them can potentially serve as a gateway toward the development of the prevention and treatment of the infection.

\section{FUNDING}

No funding sources.

\section{COMPETING INTEREST}

None declared.

\section{ETHICAL APPROVAL}

Not required

\section{ACKNOWLEDGEMENT}

We acknowledge Dr. Fawzia Alotaibi for reviewing the manuscript.

\section{REFERENCES}

Afzal A. (2020). Molecular diagnostic technologies for COVID-19: Limitations and challenges. Journal of Advanced Research 26, 149-159.
Ahmad, T. and Rodriguez-Morales, A. J. (2020). Emergence of COVID-19 (formerly 2019-novel coronavirus): A new threat from China. Revista Panamericana de Enfermedades Infecciosas 2(2), 3738.

Alandijany, T. A., Faizo, A. A. and Azhar, E. I. (2020). Coronavirus disease of 2019 (COVID-19) in the Gulf Cooperation Council (GCC) countries: Current status and management practices. Journal of Infection and Public Health 13(6), 839-842.

Anderson, R. M., Fraser, C., Ghani, A. C., Donnelly, C. A., Riley, S., Ferguson, N. M. and Hedley, A. J. (2004). Epidemiology, transmission dynamics, and control of SARS: The 2002-2003 epidemic. Philosophical Transactions of the Royal Society of London. Series B: Biological Sciences 359(1447), 1091-1105.

Arons, M. M., Hatfield, K. M., Reddy, S. C., Kimball, A., James, A., Jacobs, J. R. and Tanwar, S. (2020). Pre-symptomatic SARS-CoV-2 infections and transmission in a skilled nursing facility. New England Journal of Medicine 382, 2081-2090.

Assiri, A., McGeer, A., Perl, T. M., Price, C. S., Al Rabeeah, A. A., Cummings, D. A. and Madani, H. (2013). Hospital outbreak of Middle East respiratory syndrome coronavirus. New England Journal of Medicine 369(5), 407-416.

Bagheri, S. H. R., Asghari, A. M., Farhadi, M., Shamshiri, A. R., Kabir, A., Kamrava, S. K. and Ghalehbaghi, B. (2020). Coincidence of COVID-19 epidemic and olfactory dysfunction outbreak. Medical Journal of the Islamic Republic of Iran 34, 62.

Bai, Y., Yao, L., Wei, T., Tian, F., Jin, D. Y., Chen, L. and Wang, M. (2020). Presumed asymptomatic carrier transmission of COVID-19. Jama 323(14), 1406-1407.

BBC News. (2020). Trials combine Oxford and Sputnik vaccine. BBC: https://www.bbc.com/news/health [Retrieved on 11 December 2020].

Cai, J., Sun, W., Huang, J., Gamber, M., Wu, J. and He, G. (2020). Indirect virus transmission in cluster of COVID-19 cases, Wenzhou, China, 2020. Emerging Infectious Diseases 26(6), 1343.

Centers for Disease Control. (2019). How COVID-19 Spreads. $\quad$ CDC: https://www.cdc.gov/widgets/micrositeCollectionViewe rMed/index.html?chost=www.nih.gov\&cpath=/healthinformation/coronavirus\&csearch=fbclid\%3DIwAR2Yh q8hp1zXbTRWmT35UEnnOW6H7UFWGb9ncsBgX67 7BMqIS0zX65RJA 4\&chash=!\%2Fdetail\%2F403327\& ctitle=Coronavirus $\% 20$ (COVID-

19)\%20\%7C\%20National\%20Institutes $\% 20$ of $\% 20 \mathrm{Hea}$ Ith\%20(NIH)\&wn=micrositeCollectionViewerMed\&wf=/ widgets/micrositeCollectionViewerMed/\&wid=microsite CollectionViewerMed1\&mMode $=$ widget $\& \mathrm{mPage}=\& \mathrm{mC}$ hannel=\&cdcCollectionid $=403305 \&$ cdc Theme $=$ theme 1\&cdcGeotag=\%7B\%27continent\%27:\%20\%2762551 49\%27,\%20\%27country\%27:\%20\%276252001\%27,\% 20\%27state $\% 27: \% 20 \% 27 \% 27, \% 20 \% 27$ region $\% 27: \%$ 
20\%27\%27\%20\%7D\&cdcDataid=404908\&chashOptM ode=out\#!/ [Retrieved on 18 May 2020]

Cheng, V., Wong, S. C., Chen, J., Yip, C., Chuang, V., Tsang, O., Sridhar, S., Chan, J., Ho, P. L. and Yuen, K. Y. (2020). Escalating infection control response to the rapidly evolving epidemiology of the Coronavirus disease 2019 (COVID-19) due to SARSCoV-2 in Hong Kong. Infection Control \& Hospital Epidemiology 41(5), 493-498.

Corman, V. M., Rabenau, H. F., Adams, O., Oberle, D., Funk, M. B., Keller-Stanislawski, B., Timm, J., Drosten, C. and Ciesek S. (2020). SARS-CoV-2 asymptomatic and symptomatic patients and risk for transfusion transmission. Transfusion 60(6), 11191122.

Day, M. (2020). Covid-19: Identifying and isolating asymptomatic people helped eliminate virus in Italian village. BMJ 368, m1165.

Delamater, P. L., Street, E. J., Leslie, T. F., Yang, Y. T. and Jacobsen, K. H. (2019). Complexity of the basic reproduction number (R0). Emerging Infectious Diseases 25(1), 1-4.

Ebrahim, S. H. and Memish, Z. A. (2020). Saudi Arabia's drastic measures to curb the COVID-19 outbreak: Temporary suspension of the Umrah pilgrimage. Journal of Travel Medicine 27(3), taaa029.

Fan, C., Li, K., Ding, Y., Lu, W. L. and Wang, J. (2020). ACE2 expression in kidney and testis may cause kidney and testis damage after 2019-nCoV infection. Frontiers in Medicine 7, Article 563893.

Fiolet, T., Guihur, A., Rebeaud, M. E., Mulot, M., Peiffer-Smadja, N. and Mahamat-Saleh, Y. (2020). Effect of hydroxychloroquine with or without azithromycin on the mortality of coronavirus disease 2019 (COVID-19) patients: A systematic review and meta-analysis. Clinical Microbiology and Infection 27(1), $19-27$.

Gelardi, M., Trecca, E., Cassano, M. and Ciprandi, G. (2020). Smell and taste dysfunction during the COVID-19 outbreak: A preliminary report. Acta Biomed 91(2), 230-231.

Guo, Y. R., Cao, Q. D., Hong, Z. S., Tan, Y. Y., Chen, S. D., Jin, H. J. and Yan, Y. (2020). The origin, transmission and clinical therapies on coronavirus disease 2019 (COVID-19) outbreak- an update on the status. Military Medical Research 7(1), 1-10.

Hatipoğlu, N. (2020). The "New" problem of humanity: New Coronavirus (2019-nCoV/COVID-19) disease. Medical Journal of Bakirkoy 16(1), 1-8.

He, X., Lau, E. H., Wu, P., Deng, X., Wang, J., Hao, X. and Mo, X. (2020). Temporal dynamics in viral shedding and transmissibility of COVID-19. Nature Medicine 26, 672-675.

Huang, Y., Chen, S., Yang, Z., Guan, W., Liu, D., Lin, Z. and Li, Y. (2020). SARS-CoV-2 viral load in clinical samples of critically ill patients. American Journal of Respiratory and Critical Care Medicine 201(11), 14351438.
Jackwerth, J. (2020). What do index options teach us about Covid-19? The Review of Asset Pricing Studies 10(4), 618-634.

Jin, Y., Yang, H., Ji, W., Wu, W., Chen, S., Zhang, W. and Duan, G. (2020). Virology, epidemiology, pathogenesis, and control of COVID19. Viruses 12(4), 372.

Johns Hopkins University and Medicine (2020). Coronavirus resource center. https://coronavirus.jhu.edu/data/mortality. [Retrieved on 14 October 2020].

Kakhki, R. K., Kakhki, M. K. and Neshani, A. (2020). COVID-19 target: A specific target for novel coronavirus detection. Gene Reports 100740.

Kashour, Z., Riaz, M., Garbati, M. A., AIDosary, O., Tlayjeh, H., Gerberi, D., Murad, M. H., Sohail, M. R., Kashour, T. and Tleyjeh, I. M. (2020). Efficacy of chloroquine or hydroxychloroquine in COVID-19 patients: A systematic review and meta-analysis. The Journal of Antimicrobial Chemotherapy 76(1), 30-42.

Lai, C. C., Shih, T. P., Ko, W. C., Tang, H. J. and Hsueh, P. R. (2020). Severe acute respiratory syndrome coronavirus 2 (SARS-CoV-2) and corona virus disease-2019 (COVID-19): The epidemic and the challenges. International Journal of Antimicrobial Agents 55(3), 105924.

Lake, M. A. (2020). What we know so far: COVID-19 current clinical knowledge and research. Clinical Medicine 20(2), 124.

Lam, D. S., Wong, R. L. M., Lai, K. H. W., Ko, C. N., Leung, H. Y., Lee, V. Y. W. and Huang, S. S. (2020). COVID-19: Special precautions in ophthalmic practice and FAQs on personal protection and mask selection. The Asia-Pacific Journal of Ophthalmology 9(2), 6777.

Lauer, S. A., Grantz, K. H., Bi, Q., Jones, F. K., Zheng, Q., Meredith, H. R. and Lessler, J. (2020). The incubation period of coronavirus disease 2019 (COVID-19) from publicly reported confirmed cases: Estimation and application. Annals of Internal Medicine 172(9), 577-582.

Li, X., Geng, M., Peng, Y., Meng, L. and Lu, S. (2020). Molecular immune pathogenesis and diagnosis of COVID-19. Journal of Pharmaceutical Analysis 10(2), 102-108.

Liu, Y., Gayle, A. A., Wilder-Smith, A. and Rocklöv, J. (2020). The reproductive number of COVID-19 is higher compared to SARS coronavirus. Journal of Travel Medicine 27(2), taaa021.

Lo, I. L., Lio, C. F., Cheong, H. H., Lei, C. I., Cheong, T. H., Zhong, X. and Sin, N. N. (2020). Evaluation of SARS-CoV-2 RNA shedding in clinical specimens and clinical characteristics of 10 patients with COVID-19 in Macau. International Journal of Biological Sciences 16(10), 1698.

Lu, X., Whitaker, B., Sakthivel, S. K., Kamili, S., Rose, L. E., Lowe, L., Mohareb, E., Elassal, E. M., Alsanouri, T., Haddadin, A. and Erdman, D. D. (2014). Real-time reverse transcription-PCR assay panel for Middle East respiratory syndrome coronavirus. 
Journal of Clinical Microbiology 52(1), 67-75.

Malik, Y. A. (2020). Properties of coronavirus and SARSCoV-2. The Malaysian Journal of Pathology 42(1), 311.

Mancia, G., Rea, F., Ludergnani, M., Apolone, G. and Corrao, G. (2020). Renin-angiotensin-aldosterone system blockers and the risk of Covid-19. New England Journal of Medicine 382, 2431-2440.

Merten, O.-W. (2002). Virus contaminations of cell cultures - a biotechnological view. Cytotechnology 39(2), 91-116.

Ong, S. W. X., Tan, Y. K., Chia, P. Y., Lee, T. H., Ng, O. T., Wong, M. S. Y. and Marimuthu, K. (2020). Air, surface environmental, and personal protective equipment contamination by severe acute respiratory syndrome coronavirus 2 (SARS-CoV-2) from a symptomatic patient. Jama 323(16), 1610-1612.

Parry, J. (2020). China coronavirus: Cases surge as official admits human to human transmission. BMJ $368, \mathrm{~m} 236$.

Pharmaceutical Technology (2020). COVID-19 in the Middle East: Coronavirus-affected countries Pharmaceutical Technology: https://www.pharmaceutical-

technology.com/features/coronavirus-affectedcountries-middle-east-covid-19/ [Retrieved on 18 May 2020].

Riou, J. and Althaus, C. L. (2020). The pattern of early human-to-human transmission of Wuhan 2019 novel coronavirus (2019-nCoV), December 2019 to January 2020. Eurosurveillance 25(4), 2000058.

Rothan, H. A. and Byrareddy, S. N. (2020). The epidemiology and pathogenesis of coronavirus disease (COVID-19) outbreak. Journal of Autoimmunity 109, 102433.

Setti, L., Passarini, F., Gennaro, G. D., Barbieri, P., Perrone, M. G., Borelli, M. and Miani, A. (2020). Airborne transmission route of COVID-19: Why 2 Meters/6 feet of inter-personal distance could not be enough. Environmental Research and Public Health 17(8), 2932.

Shang, J., Ye, G., Shi, K., Wan, Y., Luo, C., Aihara, H. and Li, F. (2020). Structural basis of receptor recognition by SARS-CoV-2. Nature 581, 221-224.

Shereen, M. A., Khan, S., Kazmi, A., Bashir, N. and Siddique, R. (2020). COVID-19 infection: Origin, transmission, and characteristics of human coronaviruses. Journal of Advanced Research 24, 9198.

Siddiqi, H. K., and Mehra, M. R. (2020). COVID-19 illness in native and immunosuppressed states: A clinical-therapeutic staging proposal. The Journal of Heart and Lung Transplantation 39(5), 405-407.

Somily, A. M. and BaHammam, A. S. (2020). Coronavirus disease-19 (severe acute respiratory syndrome-coronavirus-2) is not just simple influenza: What have we learned so far? Journal of Nature and Science of Medicine 3(2), 79-82.

STAT News (2020). COVID-19 drugs and vaccine tracker. Stat News: https://www.statnews.com/feature/coronavirus/drugsvaccines-tracker/ [Retrieved on 18 May 2020].

Tang, Y. W., Schmitz, J. E., Persing, D. H. and Stratton, C. W. (2020). Laboratory diagnosis of COVID-19: Current issues and challenges. Journal of clinical Microbiology 58(6), e00512-e00520.

Templeton, K. (2020). Diagnosis of SARS-CoV-2 - What are the options? The University of Edinburgh: https://www.ed.ac.uk/edinburgh-infectiousdiseases/covid-19/covid-19-events-andactivities/edinburgh-coronavirus-workshop/talksummaries/diagnosis-sars-cov-2 [Retrieved on May 18, 2020].

The Economic Times (2020). Saudi Arabia races to contain epidemic in Islam's holiest city. The Economic Times:

https://economictimes.indiatimes.com/news/internatio nal/world-news/saudi-arabia-races-to-containepidemic-in-islams-holiestcity/articleshow/75135742.cms?utm source $=$ contentof interest\&utm medium=text\&utm campaign=cppst [Retrieved on 14 October 2020].

The Guardian (2020). Saudi Arabia seals off Shia Qatif region over coronavirus fears. The Guardian: https://www.theguardian.com/global/2020/mar/09/sau di-arabia-seals-off-shia-qatif-region-over-coronavirusfears [Retrieved on 14 October 2020].

The National (2020). Coronavirus in the Middle East: Lockdowns extended across the region. The National: https://www.thenational.ae/world/mena/coronavirus-inthe-middle-east-lockdowns-extended-across-theregion-1.995673 [Retrieved on 18 May 2020].

University of Edinburgh (2020). Clinical aspects of COVID-19. https://www.ed.ac.uk/edinburgh-infectiousdiseases/covid-19/covid-19-events-andactivities/edinburgh-coronavirus-workshop/talksummaries/clinical-aspects-covid-19. [Retrieved on 9 May 2020].

van den Driessche, P. (2017). Reproduction numbers of infectious disease models. Infectious Disease Modelling 2(3), 288-303.

van Doremalen, N., Bushmaker, T., Morris, D. H., Holbrook, M. G., Gamble, A., Williamson, B. N. and Lloyd-Smith, J. O. (2020). Aerosol and surface stability of SARS-CoV-2 as compared with SARSCoV-1. New England Journal of Medicine 382(16), 1564-1567.

van Riel, D., and de Wit, E. (2020). Next-generation vaccine platforms for COVID-19. Nature Materials 19, 810-812.

Wei, W. E., Li, Z., Chiew, C. J., Yong, S. E., Toh, M. P. and Lee, V. J. (2020). Pre-symptomatic transmission of SARS-CoV-2-Singapore, January 23-March 16, 2020. Morbidity and Mortality Weekly Report 69(14), 411.

WHO, World Health Organization (2020a). WHO Timeline - COVID-19. WHO https://www.who.int/news-room/detail/27-04-2020who-timeline---covid-19 [Retrieved on 2 May 2020]. 
Malays. J. Microbiol. Vol 17(2) 2021, pp. 227-243

DOI: http://dx.doi.org/10.21161/mjm.200903

WHO, World Health Organization (2020b). Naming the Coronavirus disease (COVID-2019) and the virus that causes

it.

WHO:

https://www.who.int/emergencies/diseases/novelcoronavirus-2019/technical-guidance/naming-thecoronavirus-disease-(covid-2019)-and-the-virus-thatcauses-it. [Retrieved on 2 March 2020].WHO, World Health Organization (2020c). Modes of transmission of virus causing COVID-19: Implications for IPC precaution recommendations. WHO: https://www.who.int/newsroom/commentaries/detail/modes-of-transmission-ofvirus-causing-covid-19-implications-for-ipc-precautionrecommendations [Retrieved on 18 May 2020].

WHO, World Health Organization (2020d). Coronavirus disease 2019 (COVID-19) Situation Report - 73. WHO: https://www.who.int/docs/defaultsource/coronaviruse/situation-reports/20200402sitrep-73-covid-19.pdf [Retrieved on 18 May 2020].

WHO, World Health Organization (2020e). WHO Coronavirus Disease (COVID-19) Dashboard: https://covid19. who.int/?gclid=CjwKCAjw2dD7BRASEi wAWCtCb7CsC6Of3cNYCToMyv NGzf2m6nsBJv1tfTS3ycwT6ZTyeZ3WXSTBoCB1MQAvD BwE [Retrieved on 14 October 2020].

Worldometer (2020). COVID-19 Coronavirus pandemic. Worldometer: https://www.worldometers.info/coronavirus/ [Retrieved on June 7, 2020].

Xu, Z., Shi, L., Wang, Y., Zhang, J., Huang, L., Zhang, C. and Tai, Y. (2020). Pathological findings of COVID19 associated with acute respiratory distress syndrome. The Lancet Respiratory Medicine 8(4), 420-422.

Yezli, S. and Khan, A. (2020). COVID-19 social distancing in the Kingdom of Saudi Arabia: Bold measures in the face of political, economic, social and religious challenges. Travel Medicine and Infectious Disease 21, 101692.

Zhang, X., Chen, X., Zhang, Z., Roy, A. and Shen, Y. (2020a). Strategies to trace back the origin of COVID19. The Journal of Infection 80(6), e39-e40.

Zhang, Z., Zhang, L. and Wang, Y. (2020b). COVID-19 indirect contact transmission through the oral mucosa must not be ignored. Journal of Oral Pathology \& Medicine 49(5), 450-451.

Zhou, P., Yang, X. L., Wang, X. G., Hu, B., Zhang, L., Zhang, W. and Chen, H. D. (2020). A pneumonia outbreak associated with a new coronavirus of probable bat origin. Nature 579(7798), 270-273. 